\title{
Synchronous epithelioid stromal tumour and lipoma in the stomach
}

\author{
Nabeel Al-Brahim MD, Jasim Radhi MD FRCPath FRCPC, John Gately MD FRCSC
}

N Al-Brahim, J Radhi, J Gately. Synchronous epithelioid stromal tumour and lipoma in the stomach. Can J Gastroenterol 2003;17(6):374-375.

An 82-year-old man presented with upper gastrointestinal bleeding. A polypoid lesion of the distal stomach with focal ulceration was seen at endoscopy. This was treated by a partial gastrectomy. The resected stomach contained two separate tumours near the pylorus: a gastrointestinal stromal tumour (GIST) and an adjacent lipoma.

The literature includes case reports of synchronously occurring GIST and adenocarcinoma, GIST and mucosa-associated lymphoid tissue lymphoma and GIST and carcinoid tumour. Herein is the first case report of two distinct mesenchymal tumors coexisting in the stomach.

Key Words: Epithelioid tumour; Gastrointestinal stromal tumour; Lipoma

astrointestinal stromal tumours (GISTs) are a heteroge$J_{\text {neous group of mesenchymal tumours; their clinical and }}$ histological features vary depending on their location within the gastrointestinal tract. They occur predominantly in older patients and are equally distributed between men and women. Seventy per cent of the tumours occur in the stomach, $20 \%$ to $30 \%$ in the small intestine and less than $10 \%$ in the esophagus, colon and rectum (1). Lipomas are rarely found in the stomach. They are asymptomatic, but may occasionally cause obstruction or bleeding.

It is very unusual for different tumours to coexist in the same organ. In the stomach, GISTs have been found alongside mucosa-associated lymphoid tissue lymphoma (2) and adenocarcinoma $(2,3)$. In the small intestine, the coexistence of a GIST and carcinoid tumour of the ampulla has been reported (4).

The present report describes the synchronous occurrence of a GIST and a submucosal lipoma in the antrum of the stomach. This combination of two mesenchymal gastric tumours has not previously been described in the literature.

\section{CASE PRESENTATION}

An 82-year-old man presented with a three-day history of abdominal pain and melena following alcohol ingestion. Previous history included an episode of upper gastrointestinal bleeding with melena in 1988. Endoscopy at that time demonstrated a small polypoid lesion with an apical ulcer. A biopsy of the lesion showed hyperplastic mucosa with ulceration, but no malignancy. The patient was observed for few days and repeat endoscopy showed that the ulcer had healed.

\author{
Simultanéité d'une tumeur cytogène \\ épithélioïde et d'un lipome de l'estomac
}

Un homme de 82 ans s'est présenté avec une hémorragie gastrointestinale supérieure. Une lésion polypoïde de l'estomac distal avec ulcération focale a été décelée à l'endoscopie. Ce trouble a été traité au moyen d'une gastrectomie partielle. L'estomac réséqué contenait deux tumeurs distinctes près du pylore : une tumeur cytogène gastro-intestinale (TCGI) et un lipome adjacent.

La documentation scientifique inclut des rapports de cas de TCGI et d'adénocarcinome, de TCGI et de lymphome des tissus lymphoïdes associés à la muqueuse ainsi que de TCGI et de tumeur carcinoïde. C'est le premier rapport de cas de deux tumeurs mésenchymateuses distinctes coexistant dans l'estomac. 


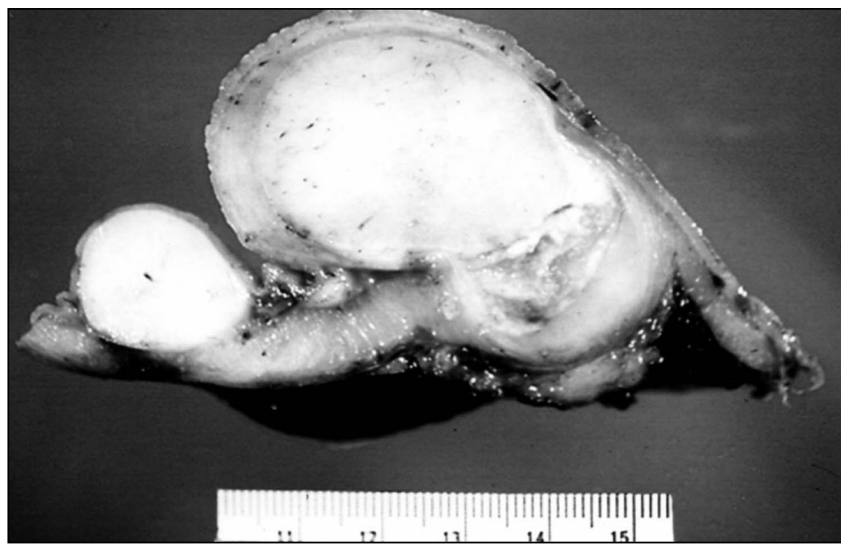

Figure 1) Macroscopic appearance of gastric antral lesions (large gastrointestinal stromal tumour and small lipoma)

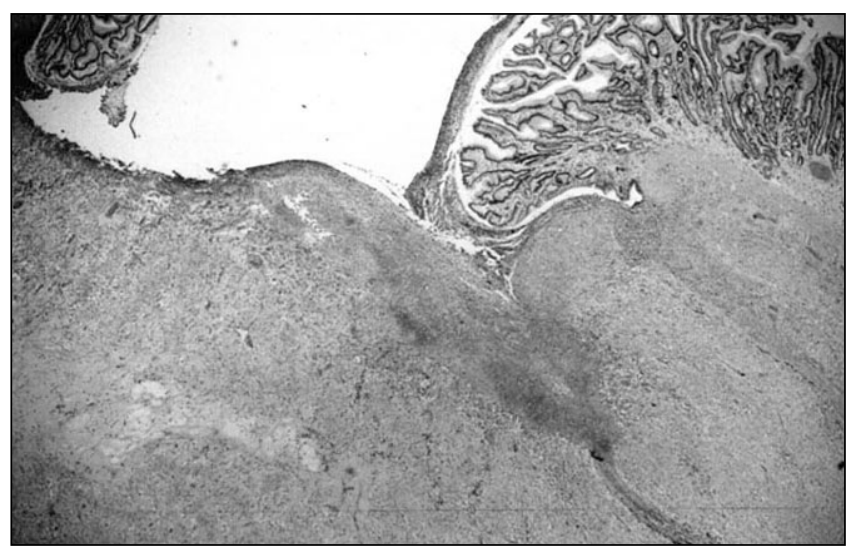

Figure 2) Microphotograph of ulcerated gastrointestinal stromal tumour (hematoxylin and eosin stain, original magnification $\times 4$ )

\section{DISCUSSION}

GISTs are mesenchymal heterogeneous neoplasms that arise throughout the gastrointestinal tract. The presenting symptoms depend on tumour size and site. The most common symptom in patients with gastric GISTs is upper gastrointestinal bleeding. There is recent evidence that the cells in these tumours have many features of interstitial cells of Cajal (5). Predicting the clinical behaviour of these tumours is notoriously difficult. However, a recent study (6) has demonstrated that benign gastric GISTs could be diagnosed by a constellation of histological features other than counting mitosis or measuring tumour size. In addition, there are individual morphological features that are associated with an aggressive clinical course, including tumour size greater than $7 \mathrm{~cm}$, mucosal invasion, cellularity in epithelioid type, high nuclear grade, mitotic count higher than five mitoses per 50 high power field and myxoid changes (6).

Lipomas of the gastrointestinal tract are benign, single and slow growing lesions. They occur most commonly in the colon and small bowel, and very rarely in the stomach. Most are detected incidentally, but they can cause obstruction or bleeding (7).

The synchronous occurrence of epithelial and stromal tumours in the stomach has been reported rarely in the literature. To our knowledge this represents the first case report of two synchronous mesenchymal tumours of the stomach. Coincidence alone could account for such an association.

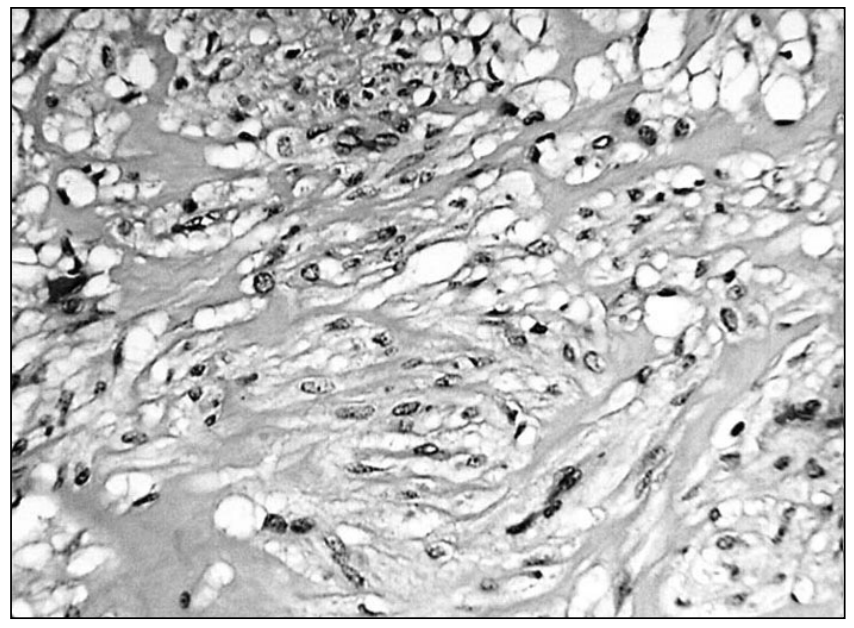

Figure 3) High power view of epithelioid gastrointestinal stromal tumour (hematoxylin and eosin stain, original magnification $\times 20$ )

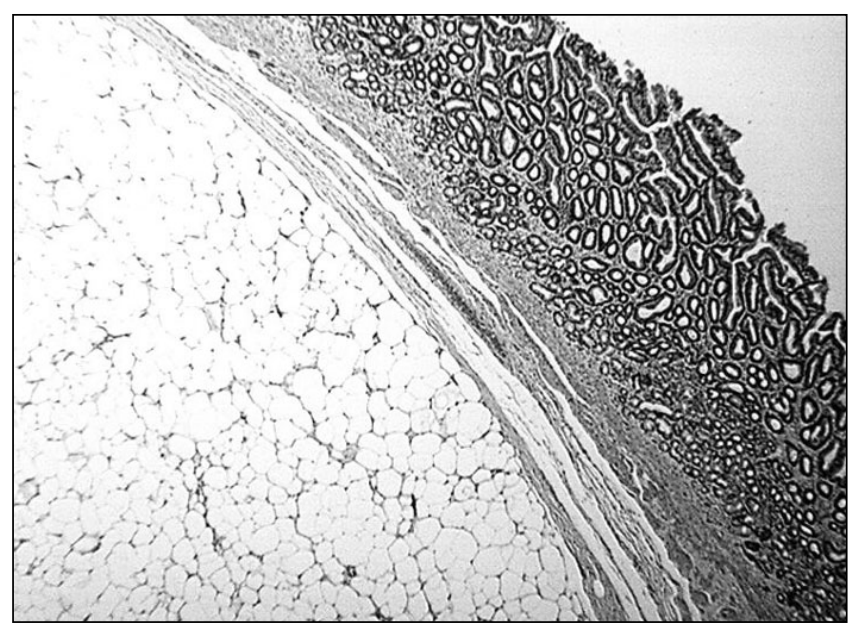

Figure 4) Gastric lipoma (hematoxylin and eosin stain, original magnification $\times 4$ )

\section{REFERENCES}

1. Miettinen M, Satlono-Rickala M, Lasota J. Gastrointestinal stromal tumour: Recent advances in understanding their biology. Hum Pathol 1999;30:1213-20.

2. Kaffes A, Hughes L, Holliushead J, Katelaris P. Synchronous primary adenocarcinoma, mucosa-associated lymphoid tissue lymphoma and a stromal tumour in a Helicobacter pylori-infected stomach. J Gastroenterol Hepatol 2002;17:1033-6.

3. Maiorana M, Fante R, Maria Casinaro A, Adriana Fano R. Synchronous occurrence of epithelial and stromal tumour in the stomach: a report of 6 cases. Arch Pathol Lab Med 2000;124:682-6.

4. Kantazas G, Kouraklis G, Karayiannakis A, Patapis P, Givalos N, Kaperonis E. Ampullary carcinoid and jujenal stromal tumour associated with Von Reckinghouen's disease presenting as gastrointestinal bleed and jaundice. Eur J Surg Oncol 2000;26:428-9.

5. Kindblon L, Rematti H, Aldenoborg F, et al. Gastrointestinal pacemaker Tumour (GIPACT): Gastrointestinal stromal tumour show phenotypic characteristics of the interstitial cells of Cajal. Am J Pathol 1998;152:1259-69.

6. Trupiano JK, Stewart RE, Misick C, Appelman HD, Goldblum JR. A clinicopathologic study of 77 cases with correlation of features with nonaggresive and aggressive clinical behaviors. Am J Surg Path 2002;26:705-14.

7. Taylor A, Stewart E, Dodds W. Gastrointestinal lipomas: A radiologic and pathological review. AJR 1990;55:1205-10. 


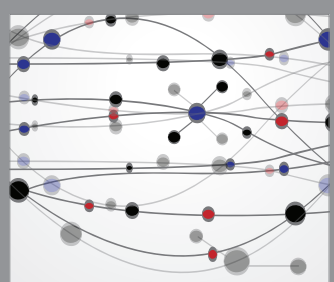

The Scientific World Journal
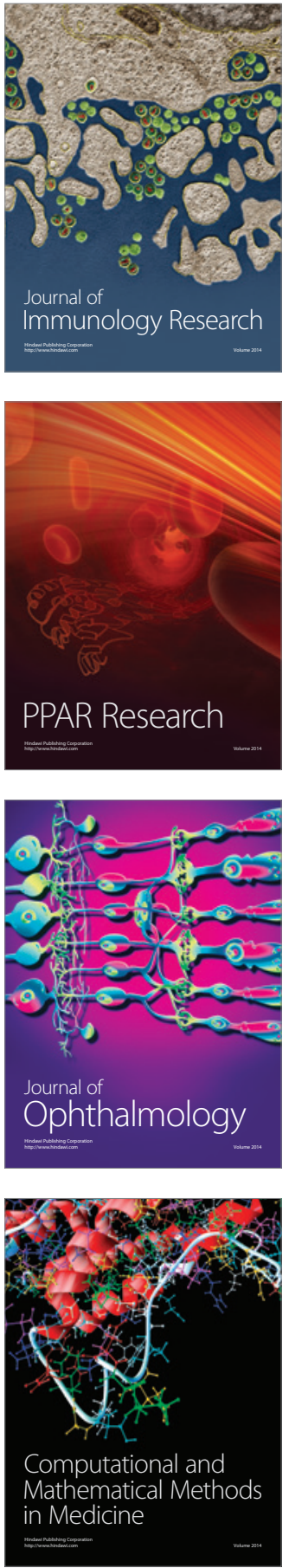

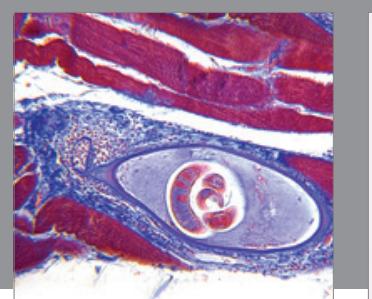

Gastroenterology Research and Practice

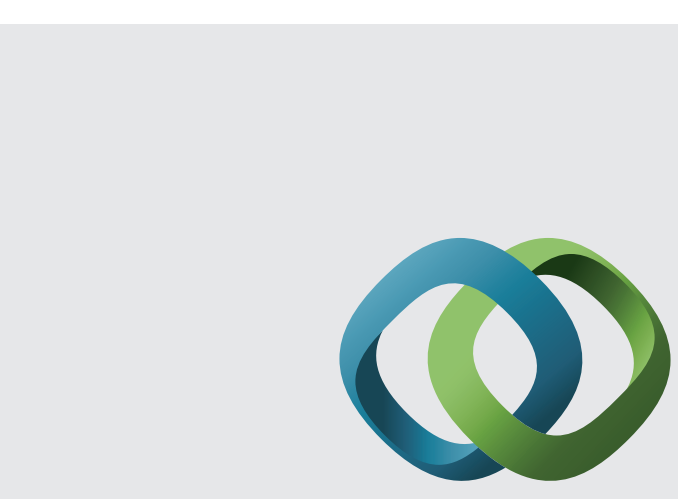

\section{Hindawi}

Submit your manuscripts at

http://www.hindawi.com
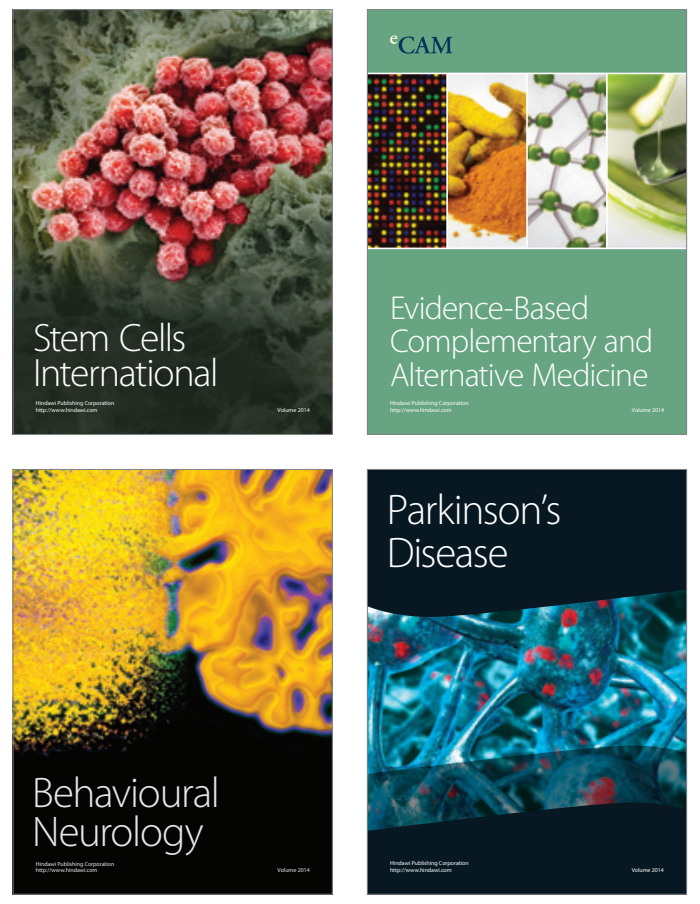
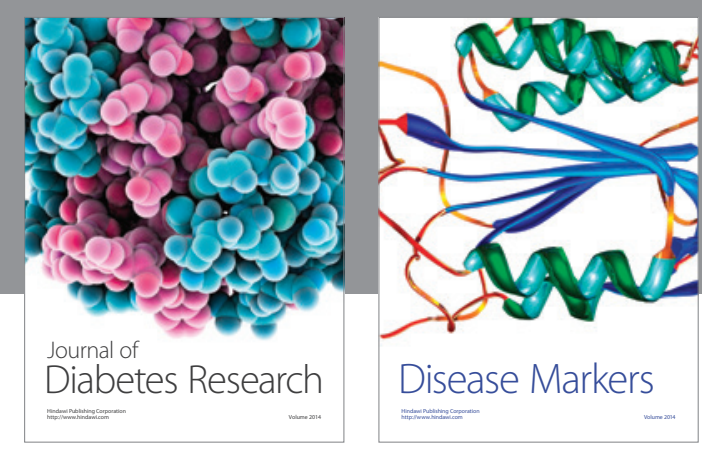

Disease Markers
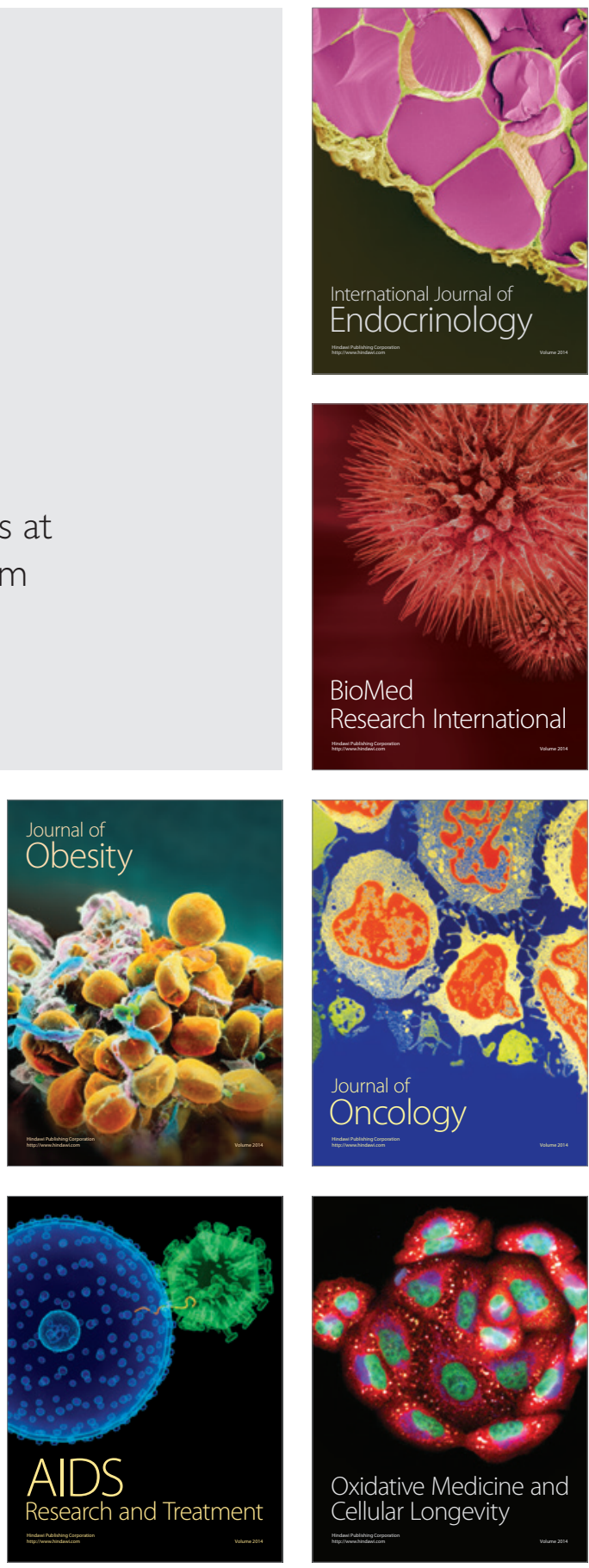